\title{
The Touring Musician: Repetition and Authenticity in Performance
}

\author{
Daniel R. McKinna \\ Brighton Institute of Modern Music \\ danmckinna@hotmail.com
}

\begin{abstract}
The research of popular music performance from the perspective of musicians is an under researched area. Drawing on research with pop and rock musicians in the UK, analyzed through Deleuzian concepts of time and repetition, this article explores the motivations to perform music live, what such a performance means and, in particular, how the almost unavoidable repetition of a tour of performances affects a sense of authenticity in the experience of the musical performance. What are the special or memorable moments in a performance for the musicians? How do these moments occur and is it is possible to repeat them? Deleuze's syntheses of time are used to help explain this phenomenon.
\end{abstract}

Keywords: live music, performance, musicians, repetition, authenticity

\section{Introduction}

Having been a professional musician for fifteen years or so, I have performed during many live music tours of varying styles, sizes, lengths and success. Touring is inevitably about playing on consecutive nights with the same musicians and more often than not the same songs, often in the same order. Yet the idea that some performances are better, or that sections of a performance contain some unexplained magic are a feature of every tour. The special moments are often what both the audience and the musicians are seeking, but it is difficult to understand what the circumstances are that allow musician and audience to be "taken out of themselves" (Frith 2012: 521). When I read the article Going Through the Motions: Why Pete Townshend's Windmill Works Even When He Doesn't Mean It (Quirk and Toynbee 2005), it resonated with me as a touring musician and led me to explore issues that arose by playing more or less the same material night after night. For example, how are the magic moments of a performance achieved? What does it mean for the touring musician to travel to different places playing the same show to a new audience? How does this affect the performance? It also crucially opened questions of what live performance means within popular music and academic study.

The live experience of popular music is as important as ever with bands constantly touring and the recent explosion of music festivals. ${ }^{1}$ Although during the mid-1990s live music was described as being marginalized (Thornton 1995: 48), the first decade of the $21^{\text {st }}$ century has been particularly prosperous for the live music industry in the US (Deloitte 2011). According to the Financial Times (2010: web source), in Britain "by 2008 the live sector was bigger than the recording industry's, and not just because of falling sales in recordings but because of a 'boom in live music"'. Yet, Jason Toynbee 
argues that, in the study of popular music, live performance is a "topic, which academics in popular music studies don't often discuss" (Quirk and Toynbee 2005: 404). Wills and Cooper (1988) have conducted research into the stresses involved as a popular musician, of which touring is one, and they provide insights into what it means to be a working musician. Frith, Brennan, Cloonan and Webster recently engaged in the recent research project Live Music in the UK and have just published, in 2013, the first volume of The History of Live Music, addressing the years 1950 to 1967, which includes one chapter on being a musician. However, the experience of touring and repeated live music performances seem to have otherwise been overlooked in music studies, which this paper wishes to rectify.

One of the main issues concerning live performance is how the performance itself can establish an experience of authenticity in the music and the musicians. The notion of authenticity in music has many layers; in the words of Thornton (1995: 26), this occurs when the music "rings true or feels real, when it has credibility and comes across as genuine" (italics in original). It can be understood as when a musical form is "rendered essential to a subculture or integral to a community" (ibid: 29). During a live music performance, the audience is able to confirm a shared common sense that the band's music is theirs. Confirming what the audience knows prior to the live experience, via artifacts such as recordings, photos, press, internet and video feels authentic. According to Auslander (1998: 12), "live rock performance is precisely about establishing the authenticity of the recorded sound but also visual evidence of that production by musicians whose appearance suggests that they are its legitimate makers".

So given that authenticity is a central motivation to engage in live music performance, what does this mean to the musician? Can every performance be made to feel authentic? Does each show on a tour mean as much as the other and how can we account for the special moments? Do some seem more real than others, and are those acts that are spontaneous rather than rehearsed more, or less, authentic? I wish to explore some of these questions by concentrating on professional musicians performing original music, as opposed to the many musicians that make a living from performing in covers bands, which Frith (2007) describes as secondary performance. Drawing on the circle of musicians with whom I have become acquainted over the years of being a musician, I contacted twenty-five, asking questions concerning what it means to play live, what the factors are that contribute to the fluctuation and change in performance, and how touring affects their performance and mindset. In addition I closely interviewed five musicians in the band I toured with during 2012.

In the analysis of the material, the discussion will draw some preliminary parallels between the repetition of performance and Deleuzian concepts of time, repetition and difference, to help elucidate the affects of repetition on tour. In doing so, performance is discussed in conjunction with the notion of 'becoming' and the idea of the schizoid musician, as laid out by Szekely (2003) with reference to Deleuze and Guattari's concept of "schizoanalysis", which is best understood in terms of the search for the truth, or authenticity, in the music by opening up to the possibilities in performance.

\section{Live Performance in Theory}

Within the history of popular music the main focus for the music industry, and our own conception of it, has been based on music recording, rather than on live music performance. According to Frith, Brennan, Cloonan and Webster (2013: ix), academic studies too often "over-privilege[s] the recording sector at the expense of the sector in which most musicians in all genres have been located historically, the live arena" Yet, in recent years, the importance of live music is as strong as that of recording, if not stronger, in the age of digital music distribution. Frith (2010: 2) describes how live performance is a "continuously necessary aspect of musical culture", and how the relationship between live performance and recorded music is one that is constantly 
changing. This relationship is complex. Gracyk (1996: 75) insists that, during the 1980s and 1990s the recording had become the primary aesthetic form: the "recording is the most characteristic medium of rock". He also suggests that live performance is just another visual representation or a means of promoting the recording. Performing live cannot be as important as it is to both musician and audience if it is merely the transfer of "the music's main stylistic features, supplemented by theatrics" (ibid: 77). Although he goes on to say that the live concert creates and confirms a bond between performer and audience, he still return to the idea that it is basically a "commercial exchange".

However, Gracyk's position does not fully take into account the complex relationship between the recording and live performance. Toynbee (2000) takes issue with the idea of the recorded work being the singular authentic form due to there being present in any kind of mediatization of music a strong performative element. He describes popular music as being a processive music, in that there is an uncompleted aspect as different evolving or shifting versions are possible from its creation to the varied opportunities and potential processes of performance. Gracyk seems to overestimate the importance of the recording, but also underestimates it by not accounting for popular music's "continuous process of performance and creation" (Toynbee 2000: 56), for example through studio performance, overdubs, mixing, different versions, edits and remixing.

Live performance, though, is just one instance of performance. Auslander (2006) states that the very idea of 'live' exists only in opposition to the recording; all music would be performed live, and was, before there was the possibility of its mediatization, which is also shown by Wald (2009). Auslander cites Baudrillard in that "the very definition of the real has become that of which it is possible to give an equal reproduction" (2006: 86). The real, in this case the live, disappears so that the recording becomes more real, the hyperreal, so that the live performance becomes a re-creation of the record. However the line is not so clear-cut. Live performances have various levels of interaction with music and mediating technologies from the microphone and amplification to lighting and big screens at arena concerts. In addition, there is the possibility of live radio broadcast, recording for television or even simultaneous webcasting (see Duffett 2003). The performance may or may not be a close reproduction of the recording and, furthermore, could be a reproduction of a promotional video. Baudrillard (cited in Auslander 2006: 87) argues that there is "a collapsing of two traditional poles into each other: an IMPLOSION...", in this case an implosion of the performance and the audio production of a piece of music. This questions what is now being reproduced and what is the real. In other words, the "live performance serves to authenticate the recording but does not function explicitly as its original referent" (Auslander 2006: 91).

If we are to take authentication as a primary function of live music performance, what does authenticity mean in this context? Although Tim Quirk's discussion is centred on the magic moments in live performance, he is quick to dismiss these as being related to the authenticity of experience (Quirk and Toynbee 2005). Furthermore, authenticity is regarded as an ideological concept by Frith (2000), while Moore (2002) argues that authenticity can be used as an interchangeable term with other concepts, such as 'honest', 'genuine', 'truthful' or 'sincere'. Finally, Auslander (1998: 10) discusses authenticity in terms of rock ideology as the idea that the music is sincere and genuine as the expression of the artist; this is inherent not just in the music but also in the presence of the visual performance, so that both must be considered in determining the authenticity of a musical experience. Yet, authenticity seems a matter of interpretation, being an ascribed attribution rather than inscribed as an essential quality. In this context, our prior knowledge and experience are important, "whether we hear something as authentic depends on who we are" (Moore 2002: 210). Importantly, authenticity can be understood as a convention determined by cultural and industry practice, whereby its signs depend upon different and shifting practices according to genre (Auslander 1998). It is the belief in the music by both audience and musicians 
that enables authentication to take place (Pattie 1999). Authenticity, then, is a shared experience, knowledge and practice according to music genre or subculture, a common sense that enables us to identify what is 'true' regarding both who the artist is and the sincerity of their performance.

This paper is further concerned with the various forms of affect produced through repetition of music performances during concert tours. Very little is written on the subject. Middleton (1983) has addressed repetition in popular music but this is primarily concerned with musical structure and syntax. Although repetition of performance has been researched with regards to the concert pianist (Chaffin, Chen and Lemieux 2007), this is a detailed analysis from a psychological perspective of what is different in highly prepared performances. Tom Perchard also uses Baudrillard's idea of simulacrum to understand how Thelonius Monk's live improvisations were seen as insincere to French critics; the "looking for the authentic unheard rather than the routine replayed" (Perchard 2011: 81) chimes with themes of authenticity in repeated performance but the notion of improvised music presupposes that there should be a different version every time. Hytönen-Ng confirms the importance of improvisation in the creation of flow during jazz performance but suggests that rock and pop is limiting in its "uniform conformity" (2013: 132).

It could be argued that all forms of music contain improvisational elements and moments, whether it is the interpretation of a dynamic marking, the interaction with the physical space or the foregrounding through a solo (Gilbert 2004; Szekely 2003). In this way, we can begin to turn to interpretations of the work of Deleuze. For Gilbert it is the "rhizomatic moment of improvisation" that enables a sublime and cosmic experience, or a magic moment, while Szekely explores how improvisation in its various forms "is to join with the World, or meld with it" (Deleuze and Guattari cited in Szekely 2003: 119). This can aid us in understanding the special moments, or their possibility, in performance. However, in order to attempt to bring a greater understanding to repetition in performance of popular music, I wish to turn to Deleuze's 1968 work on difference and repetition, in which time is the central aspect to understanding repetition. By utilizing his argument, which plays through three syntheses of time, I hope to gain a deeper understanding of the sense of authenticity that occurs in the context of repetition of music performances during live touring.

In the first synthesis, time is understood to be circular and repetition in this instance is concerned with habit, which forms the foundation of time. Habit is based upon need (though not in a negative sense or absence) within which "repetition is essentially inscribed" (Deleuze 2004: 98). With regards to touring, it is defined by its habitual repetition of performance on a daily basis, and with this, by the authenticity of the accurate reproduction of the same songs night after night.

The second synthesis interprets time as linear and is associated with memory; the past is synthesized for experiences to be remembered. Repetition here is something that exists in memory, so that the present becomes a form of the past. The act of repetition then is one's memory of a prior event and the experience in time. Hence I recognize I am on tour because I have a representation of previous performances in my memory, which may not be the same as someone else's as it is linked to selfexperience. The performer can be understood as trying to authentically express ideas and feelings based on experiences from the past.

The third synthesis moves away from identity of the original form and expression of experience and forms a cut, a 'caesura', with time, but also a totality of time in that it draws together the before and after in its reordering of time. Only as something is repeated is its difference produced. Repetition is not understood as an equivalent but by its difference, what Deleuze calls "difference in itself". This form of present time is connected to the future and allows conditions for an authentic, unique, even innovative, performance, as Deleuze (2004: 113) pointed out in 1968, 
We produce something new only on condition that we repeat - once in the mode that constitutes the past, and once more in the present metamorphosis. Moreover, what is produced, the absolutely new itself, is in turn nothing but repetition: the third repetition, this time by excess, the repetition of the future as eternal return.

In this way, on tour, the identity of the previous performance is left in the past and differences are emphasized. I want to equate this third synthesis with a performance that succeeds in creating something new and exciting. This, in turn, can help an understanding of how some of the magic moments are created and also in allowing for a new level of authenticity that is based in the moment. For example, in Elina Hytönen$\mathrm{Ng}$ 's exploration of the concept of flow in jazz performance "intense", "powerful', "mystical" and "magical" moments are produced in an "environment that was often merely repetitive" (2013: 21). It is in the third synthesis that there is the exclusion of the self, in a similar way to a musician losing her or himself in the music, in order to create the sublime. The self becomes fractured "by the pure and empty form of time" so that there is a "discovery of the transcendental" (Deleuze 2004: 108-9). Deleuze seems to be giving instruction on how to live and create; habit and memory inhibit, whereas difference in itself is an opportunity to connect with everything, through a focus on being in the moment of the performance (Williams 2003: 13).

\section{The Musicians}

In order to try and explore further what live performance means in popular music, especially from the perspective of the musician, I have undertaken some research with a range of musicians during the spring of 2012 in the UK. This sample selection was largely based on having worked and performed with these musicians, while others are acquaintances l've made through being a musician. Although it is not possible in this research to represent a cross-section of all performing popular musicians according to genre, age, sex, race and nationality it was possible to gain an effective contextual understanding of their responses and insights due to my relationship with them.

There was a reasonable spread in the selection due to the varied musical work I have done over approximately fifteen years. The instruments represented were guitar, bass, drums, keyboards and vocals. Of this sample there are band members, session musicians, solo artists and singer/songwriters. The age range was fairly broad, roughly from twenty-five to fifty-five, though there was a cluster in the late thirties and early forties.

The musical styles covered were largely pop and rock, from indie/alternative to classic rock and mainstream chart pop. While some of the musicians engage with other genres (jazz, latin, classical) and one musician's band is a successful crossover collective in electronic pop jazz, it is acknowledged that the fairly narrow genre focus of the research will not be able to take into account the different approaches and ideas inherent in a wide range of styles. There are also some limitations in respondents in terms of gender, race and nationality, whereby only two women and two non-British musicians responded. As a result, the findings of this research are skewed towards white British males with an average age of forty-two, operating in genres leaning heavily towards adult pop and rock. This research therefore provides useful insights in the touring experience of (mostly) male British musicians in these two dominant genres. According to album sales figures released in 2013 by The British Recorded Music Industry (BPI), by far the two biggest selling genres are pop with $33.5 \%$, closely followed by rock with $31.3 \%$ of the share. Figures are more murky for live music but a report by PRS for Music puts music festivals as having the largest ticket sales revenue closely followed by concerts in arenas, two areas that are dominated by pop and rock (2013: 7).

Table 1 shows who the musicians were and what they do. All interviewees have given consent to their information being used, though all names are pseudonyms as some wished to remain anonymous. 
Table 1

\begin{tabular}{|c|c|c|c|c|c|c|c|}
\hline Musician & Instrument & Genre & $\begin{array}{l}\text { Session } \\
\text { musician }\end{array}$ & $\begin{array}{l}\text { Song- } \\
\text { writer }\end{array}$ & $\begin{array}{l}\text { Age } \\
\text { range }\end{array}$ & Nationality & Gender \\
\hline Ben & $\begin{array}{l}\text { Vocals, } \\
\text { Guitar }\end{array}$ & Pop/Indie & $\begin{array}{l}\text { Yes } \\
\text { (guitar) }\end{array}$ & Yes & $40-44$ & British & Male \\
\hline George & $\begin{array}{l}\text { Vocals, } \\
\text { Guitar }\end{array}$ & Rock & Some & Yes & $35-39$ & British & Male \\
\hline James & $\begin{array}{l}\text { Vocals, } \\
\text { Guitar }\end{array}$ & $\begin{array}{l}\text { Acoustic } \\
\text { Pop } \\
\text { Singer/ } \\
\text { Songwriter }\end{array}$ & No & Yes & $40-44$ & British & Male \\
\hline Jeff & $\begin{array}{l}\text { Vocals, } \\
\text { Guitar }\end{array}$ & $\begin{array}{l}\text { Two-Piece/ } \\
\text { Alternative }\end{array}$ & No & Yes & $35-39$ & British & Male \\
\hline Jonathan & Guitar & Pop/Rock & Yes & No & $35-39$ & British & Male \\
\hline Kate & $\begin{array}{l}\text { Vocals, } \\
\text { Keys }\end{array}$ & $\begin{array}{l}\text { Singer/ } \\
\text { Songwriter }\end{array}$ & Some & Yes & $55-59$ & $\begin{array}{l}\text { American/ } \\
\text { British }\end{array}$ & Female \\
\hline Mikkel & $\begin{array}{l}\text { Vocals, } \\
\text { Guitar, } \\
\text { Keys }\end{array}$ & $\begin{array}{l}\text { Singer/ } \\
\text { Songwriter }\end{array}$ & No & Yes & $35-39$ & $\begin{array}{l}\text { Faroe } \\
\text { Islands }\end{array}$ & Male \\
\hline Nikolaj & Drums & Pop/Rock & Yes & Some & $40-44$ & Danish & Male \\
\hline Patrick & Bass & $\begin{array}{l}\text { Jazz/ } \\
\text { Electronic/ } \\
\text { Pop }\end{array}$ & No & Yes & $40-44$ & British & Male \\
\hline Pedro & $\begin{array}{l}\text { Keys, } \\
\text { Guitar }\end{array}$ & $\begin{array}{l}\text { Pop/Soul/ } \\
\text { Latin }\end{array}$ & Yes & Some & $35-39$ & British & Male \\
\hline Richard & Drums & Pop/Rock & Yes & No & $50-54$ & British & Male \\
\hline Sim & Bass & $\begin{array}{l}\text { Indie/ } \\
\text { Alternative }\end{array}$ & Yes & No & $25-30$ & British & Male \\
\hline Suzanne & Vocals & Pop/Rock & No & Yes & $50-54$ & British & Female \\
\hline Tom & $\begin{array}{l}\text { Bass, } \\
\text { Mandolin, } \\
\text { Percussion, } \\
\text { Keys, } \\
\text { Guitar, } \\
\text { Backing } \\
\text { Vocals }\end{array}$ & $\begin{array}{l}\text { Indie/ } \\
\text { Alternative/ } \\
\text { Jazz }\end{array}$ & Yes & Some & $45-49$ & British & Male \\
\hline
\end{tabular}

Using email as an effective means of communication, a questionnaire was sent to the musicians to be completed in their own time (Gray 2004: 210). Despite, or possibly as a result of the musicians being personal acquaintances, it was difficult to always receive a formal response; encouragement and reminders were needed and still after that I received just fourteen complete questionnaires out of the twenty-five sent. The questionnaire itself included seventeen mainly open questions (Bell 2005: 137). The role of the musician was ascertained, along with whether they had taken part in the writing and/or recording of the music they were playing live, as well as if there was a difference in performing your own music or not. Further questions asked included what it means and what their motives are to perform live, what it means to tour and play, possibly the same thing, night after night and how things may evolve over time. They were asked what makes a gig special, do they lose themselves in the music, what their mindset is when playing and do they ever feel as though they are going through the motions.

I will also be drawing on interviews with the five other members of band I currently play bass with, which were conducted in Gijon, Spain and Porto, Portugal, towards the 
end of a twenty-one date European tour completed in March 2012. The presented names are pseudonyms, with formal consent from the interviewees. The band has existed nearly twenty years and has always operated outside of mainstream mediated culture, maintaining a loyal fan-base that enables them to be able to continue releasing records and regularly touring around the world. The music is broadly speaking of a 'dark', serious yet soulful nature and, while taking in a wide range of influences the band could be filed under alternative/indie in record shops or on iTunes. The band now consists of three of the original members (Stan, vocals; Lenny, keyboards; Alan, guitar) as well as Edward who is a long-time collaborator playing various saxophones, trumpet and keyboards and drummer Melvyn, who has been with the band for four years and is an experienced high level session musician. Given how long the band has been going the age group represented here is thirty-nine to fifty-two. All are white and British with the exception of Melvyn who is black and American. I was not able to complete one interview on tour so Melvyn completed the same questionnaire as the other musicians with two additional questions, regarding special moments and memorable gigs during the last tour.

The interviews were semi-structured (Bernard 1988: 212), recorded and lasted between twenty and thirty minutes. The content was largely the same as the questionnaires, though with some reflection included on the tour that was taking place. Given my position, the interviews could be conducted in a relaxed manner and everyone was aware of the research I was undertaking prior to the interview. Being so close to the interviewees gave me an advantage in many ways, an understanding, a way in, but I also had to beware of the obstacles and preconceptions I might bring (Becker and Faulkner 2008: 1). By being part of the tour I was involved in the daily life of a culture being studied. In this way I was, in part, adopting the ethnographic role of a participant-observer (Bernard 1988; Gray 2004;). While there are variations to be found in the roles adopted by participant-observers, their position often attempts to remain detached and absent from the text (Atkinson and Hammersley 1994; Anderson 2006). However "ethnography is not an innocent practice" (Denzin 2006: 422) and it is impossible that my involvement has not influenced the research as by using musicians I know or have worked with that there is a likelihood that experiences and opinions may well be shared, perhaps uncritically, as common sense.

\section{What Performing Live Means}

Taking live performance as the authenticating act, and given the commercial aspects of promoting an album or even making money, how does this equate with what performance means to the musician and their motivations? One respondent used the term "validation" as one of three of their motivations, which was the nearest direct reference to authenticity. The most common themes were the need to "express", "communicate" and "connect" with the audience. Although this is not a direct reference to authenticity, what the musician is trying to communicate is an honest or genuine message, or according to Kate, an "emotional truth" that is inherent in the music. By connecting to such "truth" and by wanting to communicate this to the audience during a live performance, the musicians show a desire to present themselves as "legitimate makers" of the music, the success of which depends on shared values with the audience (Auslander 1998, Leonard 2007, Moore 2002). In addition, there is a desire to feel this success, whether that is in James' description of the "buzz ... from the crowd's appreciation" or, as Stan says, the feeling of "barriers coming down", as,

Playing music for people in the same room is like, erm, that's the only way you feel a direct connection with people ... If you can connect with people....it's not really about a stage and an audience but about a bunch of people in a room making something together (Stan). 
By comparison, in the context of jazz performances, Hytönen-Ng (2013: 99) also establishes that musicians have a "great need" to develop a connection with the audience.

In popular music studies, the focus on music performance is less common than on the actual compositions and their recordings. Therefore, the level of importance given by my interviewees to performing, or "playing live", is of importance. Tom and Mikkel describe it as "everything"; James says it is "the most important part of the experience"; Jonathan feels it is "a very important part of music to me"; Kate states that it is "a very fulfilling part of my life" and for Ben it is "the best and worst of experiences". This connects with Toynbee's (2000) idea of playing live being part of the creative process and minimizes Gracyk's (1996) claims of rock no longer being a performing art (in particular during the 1990s) and live performance thereby being misrepresentative and secondary.

However, some of the interviewed musicians did refer to the commercial aspect of playing live. Claiming that his "main motive is to promote material I have helped create", Patrick was the only musician to give this as his sole reason. With the others, this appeared as a secondary motive; for Kate "there are often practical, commercial reasons for performing live (e.g. promoting a record)" and Sim stated that from the point of view of the band, rather than personally, "it's the best way to promote ourselves and reach our audience". In the case of Mikkel playing live, as well as being "everything", is also a "necessity" that gives him "the chance to write my music and work as an artist", a sentiment seconded by Melvyn in that live performance is also "a means to an end of generating enough public interest to be able to make another album". Edward, Richard, Pedro and Nikolaj, all session musicians, mentioned the importance of being paid as it is their job, although this response was never given in isolation.

There is also an element of personal and artistic fulfillment in playing live for Kate, while Richard finds it 'very rewarding'. Pedro experiences a live performance as being "at peace and at one", in part echoed by Dom who feels it is "the act of becoming yourself". Jonathan finds it fulfilling purely for "the enjoyment of playing" and Mikkel finds it "a pleasure to play music". Such comments seem to place performing live on a personal level, resonating with Deleuze's second understanding of time, taking the experience away from the wider notions of how it fits with the music business and audience as a whole.

The responses presented here are able to draw links to authenticity in that, besides the personal rewards, the personal investment and being yourself are ideas of truth and sincerity This seems to link to Deleuze's second synthesis, the linear sense of repetition, in contrast to Deleuze's goal of the "discovery of the transcendental" of the music and experience. Linear time is situated in personal experience and the "truth" of the performer. Here the dogmatic image of thought would appear to relate more directly to an "affinity with truth" and "common sense" (Deleuze 2004: 166). The audience, in turn, experiences the "truth" of the music and/or performer in a more cyclical manner, as in Deleuze's first synthesis of time, and it is common sense to identify the musician(s) as the actual producers of the music they may have already heard in its mediated forms. Following this line of thought, a musician who is enjoying playing, expressing, connecting and communicating while "at peace" and "at one", does not necessarily create a sublime experience. How, then, can one produce authentically fresh and special moments in the repeated performance of music?

\section{The Special Moments}

This research is not just concerned with trying to establish what it means to play live, but also tentatively trying to explore the special, magical, or peak, moments of playing live. Even if the same material is being played on a tour, no two gigs are likely to be the 
same, especially if we are to endorse the Deleuzian concept of repetition. Different shows will have different qualities and within them they may have magic moments. These may be, as Quirk states, "genuine onstage epiphanies" such as seeing how "the band starts out playing the song, but by the end it's the other way around - the music takes over, and it's the song that's playing the band" (Quirk and Toynbee 2005: 400). In this way the musician can be heard to be repeating through habit but can also move beyond that to an experience of performing in the empty form of time and thereby breaking with past representations. What are the factors that give rise to such conditions? On the spectrum of the band being lost in the music or "consciously try[ing] to make the crowd lose control" (ibid: 401), where does the musician find herself or himself?

Almost unanimously, a gig is felt to be special when everyone is together and everyone 'feels' it. Tom's description of it being "the rare but magical union between the band and the audience's desire, intent and fulfillment", has clear connections to how "musicians continue to believe in the possibility of getting across to an audience in the postmodern era [and] audiences continue to believe in the possibility of being touched" (Toynbee 2000: 60). Nikolaj describes a special gig as "when I get lost in the music. I connect with the rest of the band and/or the audience and forget myself", an opinion echoed by Lenny. Charles Keil describes how there is a "very human, even social, need for sympathy from all members to bend for the common result" (1966: 340) and this has clear resonances with how the musicians here describe a special gig. Getting lost in the music is something many of the musicians strive for, or "the holy grail" as Nikolaj says, although according to Richard and Stan this is not always possible to achieve and difficult to "force". Not knowing or thinking about what you are doing is often the best way of being in the flow of the music as once you start thinking about it too much you can "tighten up... or lose it completely" (Keil 2004: 3).

The jazz pianist Paul Bley describes the successful performance as "getting on the right track - the right pattern - in the right way and exerting the control and practice necessary to get it" (quoted in Keil 1966: 340). This then is concerned not only with everyone being together but also describes the technical aspects of the performance.

Finding the emotional "truth"...can only be achieved when I'm thoroughly rehearsed. If I'm under-prepared - all I can think about are the technical aspects. When I surrender to the music and forget myself and forget the technical aspects, the performance is more expressive. I would always prefer a performance that contains mistakes, but has the right vibe over a technically perfect performance with no vibe. (Kate)

The latter descriptions of performing, in which the musicians forget themselves, bring us closer to the third synthesis of time. There is a cut in time, a move beyond the habit of performance, a fracturing of the self that enables the eternal return serving "to establish a difference in kind between the average and the superior forms" (Deleuze 2004: 80).

"Vibe", "energy" and "attitude", were cited ("intangible as they are", according to Ben), as being often more important than playing the right notes. During a tour of Europe in March 2012, Alan related that despite playing the same venue two nights consecutively, feeling and technical performance were completely different. The first night was well played in a cohesive manner and "the second night in Madrid was great even though there were loads of mistakes", yet the audience response was more enthusiastic with a feeling of unity. On the same tour Lenny describes how it is "not about playing perfectly, there can be lots of mistakes, just as long as you feel there's some kind of connection between yourself, the music and the audience and the room". Ben, Pedro and Jamie approve this sentiment. Apparent here is an attempt to get to a level where they can communicate with sincerity and honesty - in other words, with authenticity - and this is more important to the audience and band than every correct note. 
The factors that contribute to the making of a special performance are for Stan "quite complicated when you get to unpick it all apart". Patrick describes it as being "too complex for me to catalog", yet various musicians attempted to list the elements involved, presented here in no particular order:

- The vibe of everybody else around you/how you feel together

- The vibe/enthusiasm of the audience

- How well prepared/rehearsed you are

- The set list

- The room/venue

- Vibe of the band

- Sound on stage

- $\quad$ Lighting

- How the day went

- How you're feeling

- How tired/awake you are

- How much you've had to drink

Vibe is a recurrent term here and its definition is often murky, being as it is "outside formal language systems" (Henriques 2011: 242). With vibe there is a feeling of shared experience and commonality through a "collective energy that can be experienced on an individual basis" (Fikentscher 2000: 81). Vibe can be the combination of various factors that is more than the sum of its parts (Wu 2010), so in the list above the vibe of the band, for example, can be dependent on several other factors identified that then affect how others experience the feeling. Although by no means exhaustive, these were the main themes that arose during this research. Some factors are to some extent in one's own control (how well rehearsed, how much you've had to drink) but the majority are limited in the amount of influence you can exert.

For Melvyn, playing live "presents the opportunity to express spontaneously, with the added challenge of doing so in a largely uncontrollable environment. Szekely (2003) uses Deleuze and Guattari's 'schizoanalysis' to develop a concept of the schizoid and paranoid musician, which seems to resonate with Deleuze's third synthesis of time. He discusses the idea of the musical-space, not in the sense of the physical but as a "fluid paradigm" where "with all the technical implements, imaginative intuitions, and methodological strategies, the performer is situated ... (in) an open territory of possibility" (ibid: 114). This open territory, then, is the site of a range of themes cited by the musicians here. It is the way in which the musician interacts with the different intensities. On the one hand, the "paranoid" musician is concerned with the technical performance, preoccupied with intention and consumed by context; looking to "force repetition" (ibid: 126, italics in original). The schizoid musician, on the other hand, may be more open to the possibilities of what might happen. They move beyond a past identity and extend outward to think, act, perform, compose (improvise), ultimately so far as to touch the impossible, what Szekely equates with the cliché of being "lost in music". This is similar to Hytönen-Ng's observation that the performer needs to move beyond technique "and relinquish conscious thought... and just become part of the music" (2013: 55). Here we get close to Deleuze and Guattari's body without organs where the music and the individual are one coherent organism whereby it is "sensed as an ecstatic, catatonic, a-personal zero degree of intensity that is in no way negative but has a positive existence" (Bogue 2004: 110).

\section{Night After Night}

Touring is inextricably linked to repetition. In its most basic way a show will be performed with the same people and often with the same music. Some tours, 
especially music shows with high levels of production, even strive to always be the same, recycling time in the process. In that case, every move is choreographed, the band play to preprogrammed clicks that are not only there to keep time during the song and allow prerecorded parts to be included, but also to determine how long the gap between each song is. Whether this is the approach or a more naturalistic one, how do musicians cope with this? How does it affect them? What bearing does repetition have on notions of authenticity or wanting to communicate genuine emotion?

Responses from the interviewees were quite varied on coping with this phenomenon, however the need to connect in some manner remained at the forefront, as Tom tries "always to connect emotionally with the music" and Jeff states that he "enjoyed connecting with new audiences." The idea of repetition of the same oeuvre actually enables the musician to be able to communicate with the music and the audience more freely; that way, they move beyond the circular movement of habit and the continuing variations of the past. In what seems like a move from "paranoid" musician (concerned with technical details) to "schizoid" musician (freely open to what might happen), James describes how "once you settle into a groove on tour you can relax about playing the right parts and concentrate on really giving a proper show. That's when it's really special". However, Kate tries to achieve the connection by equating performance to "meditation" and being able to "empty out all conscious thoughts. That usually helps to slip back in the zone". Gilbert (2004: 135) describes "opening onto a cosmic space of infinite possibilities: a moment of the musiciancomposer's becoming-music". And it is when the becoming occurs that the authentic performance is achieved allowing for a connection at a deep level with the audience (Davidson and Correia 2001: 80).

Tom, too, tries to "experience each performance as a discrete event", or as Deleuze describes, a "caesura" (2004: 112), in that it is a break with the before and after. Jonathan also talks about a "conscious" mindset that will eventually turn to playing with pure feel," although he also warns against over-familiarity that can lead to playing on "autopilot" (going absent-mindedly through the motions of the performance), "and that's the point some mistakes can be made". This points towards Deleuze's idea of repetition through memory and habit, the second synthesis, in that they inhibit new sensations as they are based on identities of the past. There is a danger of slipping into "the merely programmed or mechanical, and thus into an infelicity that haunts the desire for truth of performative deterritorialization" (Wolfreys 2009: 102). Melvyn mentions how, ironically, it can be dangerous "when a band gets really good, because the playing levels out to being excellent almost every show, and this can possibly make musicians complacent", and no longer open to new possibilities. The band's journey could be read as a cyclic journey through the syntheses of time so that a point is reached when they have broken from routine, only for that break in time to be repeated hence returning to a variation of the past rather than existing in-itself. Stan describes "a curve of when it's growing, when it's alive and then there's a curve when the good thing starts to turn in on itself". There is a danger that "every additional performance threatens to strip another little bit of the mystery away" (Quirk \& Toynbee 2005: 402), yet the dichotomy between repeated performance and the fact that you only get one chance to get something right can help to maintain a balance.

Being able to maintain the intensity required every night on tour can be difficult; James comments that "inevitably some nights are harder than others".

There's sometimes a battle in me that part of me does want to go through the motions, and the other half of me kind of just hates the whole idea of that... You've gotta feel it, you can't not feel it. If we stop feeling what we do it falls apart... It's quite a lot to ask to feel it every night on a twenty date tour, there are moments when you just don't want to. (Stan)

The musician can feel impelled to connect and be in the moment, yet it is just not always possible. Although Deleuze states the need to be open to all connections, we 
can't be conscious of it as this reinforces an image that is being recreated. By relating difference (the gig in the present) to the identical (the gig in the past) it "no longer allows anything to escape" (Deleuze 2004: 331). When this happens it elicits strong feelings: Nikolaj "hate[s] it when it happens"; Tom finds it "very depressing"; Kate becomes "very unhappy with [her] performances"; Jonathan feels "something is wrong"; and Lenny gets "angry". Of course there is the old adage that the show must go on, so that for Suzanne "you just have to be professional" and George instructs that you "don't let it show". However Richard describes how if things aren't feeling good he finds it hard to act it, but finds that as a drummer he is able to "energize the performance... [to] affect the energy on stage". This has echoes of how Quirk recounts how Pete Townshend loses the "magic" midway through a performance and in order to get it back he remembers who he is and performs his trademark move, "leaping and windmilling like he's supposed to, and before too long he isn't acting anymore" (Quirk \& Toynbee 2005: 401). In a direct echo of this Tom explains that he has "been known to fake it a bit ... in order to get into character". It is interesting in the context that Tom uses the term "character" here and later goes on to discuss what he sees as a dichotomy in rock music whereby it "relies wholly upon 'keeping it real', [and] in another sense everybody is faking it, so that the audience can see and understand how real they [the performers] are". This understanding of his role in performance correlates exactly with Pattie's description of how despite the unreal quality of performance it doesn't necessarily invalidate the music's authenticity. In fact "both the audience and the performer look to the music to provide the ultimate validation, the ultimate proof of authenticity" (1999: 4).

When asked what elements changed over the course of a tour, the set list was the most commonly cited. "The running order of songs is essential to a good show. It is all part of the performance". George continues that "get it right and it can make all the difference - to the audience and the band". This is not only to make sure that "what is working" is included (Ben, James), or to be able, as Mikkel says, to "adapt to the room, and time of day", but also because the set is what enables the musicians to be able to connect more easily and be lost in the music. For Stan "it's being able to create a journey through it that's kind of interesting, that has the turns that allow you to move... [to have] different challenges along the way".

Songs too have the ability to change over the course of a tour, for Jonathan often imperceptibly. When Kate is playing the songs night after night "arrangements would change because my grasp of the song's possibilities evolved over time". This has direct links to Toynbee's (2000) description of popular music performance as "processive", but also the musicians are once again open to the possibilities in the music, the rhizomatic moment (Gilbert 2004). Ben picks up this idea by saying "I think if songs are played a lot, then great parts and dynamics develop which ideally would be captured on record. I wish I had spent more time playing songs a lot before they were recorded. They sound better on the whole". Whether or not the songs have already been recorded, there is the possibility that something spontaneous will happen that brings a new excitement that surprises both the band and the audience (Quirk \& Toynbee 2005).

These kinds of spur of the moment left turns and excursions into the unknown can become the saving grace of a long tour. It's not unknown to then recreate a successful 'detour' on a nightly basis so it looks like it's off the cuff but is in fact kind of faked. (Ben)

A transformation is then taking place because, as Quirk and Toynbee (2005) show, when something is done nightly, it can no longer be in the spur of the moment or, in other words, act in pure and empty time. Indeed this can be viewed as a reverse of Tom's idea of faking it to get into the moment. But the question arises as to which the original or the model is, if we are to view it on a spectrum, as Quirk suggests. Is it possible to privilege one over the other, especially as each action is open to change in each repetition? If there is an infinite variation in the series that coexist "then it is no 
longer possible to regard one as originary and the other as derived, one as model and the other as copy" (Deleuze 2004: 152).

\section{Conclusion}

What, then, is the experience of authenticity in the context of repetition in live performance? The findings here are possibly skewed to pop and rock, especially with the focus on musicians from one band, and also the kind of musicians I am connected to as a result. Nevertheless, there are some genre variations amongst the researched musicians, including highly commercial pop acts. The financial rewards possible in live music cannot be ignored, yet this was not a primary focus of the responses of the performers. Although there was no direct question concerning this, they were nonetheless asked of their motivations to play live. If they did respond regarding the financial aspects, it was generally to say that money was important so they could continue as musicians. It is apparent from the musicians' accounts that live performance is an extremely important part of making music and one that cannot be demoted or ignored. There is a need for connection with the music, with fellow musicians and with the audience, yet it can also be an intensely personal experience. It is necessary to be well rehearsed and to perform well, yet mistakes and problems need not lead to a bad performance, in fact sometimes to the contrary, mistakes constitute a spontaneous act that complements Deleuze's third synthesis of time. Indeed, also for the musicians Hytönen- $\mathrm{Ng}$ (2013) interviewed, their motivation to perform was the experience of flow. There is a desire to be lost in the music and simultaneously a requirement to stay in control. Playing night after night is both an obstacle to overcome and a position of necessity to affirm. Spontaneous acts can become part of regular practice and faked moments can lead to reflexive expression.

Such positions are not absolute but shifting. Musicians may occupy different positions towards authenticity along Deleuze's axis type of repetition, but it is also possible for their location to shift according to the moment, gig or tour. Each night or event within a performance is a simulacrum, not in the negative sense of an imitation, but in that they are the "superior", hyperreal forms. Contained within these forms, or events, is an internal disparity that allows for difference within itself. Considering each night's performance in this way allows for difference in repetition, whether small or large, and for each to contain at least the possibility of the sublime. A tour can feel as though it is going through the motions if it is merely trying to produce the same thing every night, where the only differences would be material, such as a different building and audience in a horizontal, linear time line. However, by going with the feeling of the present, actively connecting with the music in the moment of its performance, with the band and the audience, it is possible to concede to "making repetition...the thought and the production of the absolutely different; making it so that repetition is, for itself, difference in itself" (Deleuze 2004: 118).

Authenticity is a key theme of this investigation, yet its importance to the musician remains ambiguous. The various threads running throughout show differing forms of authenticity, voiced in various ways that infuse motivations and aspirations. Although this may seem an obvious point, a desire to make music is apparent with all, but how they do this is different depending on who they are and what they play. Whether there is a desire to put on a good show, to get lost in the music or connect with the audience the sincerity of their intentions is what appears to be important. In other words, it is the experience of the performances that matter. Speaking at the end of the 2012 South by Southwest festival Bruce Springsteen hit upon a similar motif:

There is no right way, no pure way of doing it. There is just doing it. We live in a postauthentic world. Today authenticity is a house of mirrors. It's all just what you are bringing when the lights go down, it's your teachers, your influences, your personal history. At the end of the day it's the power and the purpose of your music that still matters. (Harris 2012.) 
I wish to propose that the post-authentic world referred to here is authenticity as experience. Throughout this paper there has been a dichotomy between the affirmation of the truth based in the real and the personal with the a-personal sublime experiences of being lost in the music. The ethnographic approach towards touring and authenticity may perhaps feel contradictory to poststructuralist concepts concerning time, truth and repetition. At first glance, authenticity appears to be located in the dogmatic image of thought as it looks for truth, finding the result proposed in the original, rediscovering "the shape of what he or she predicts" (Higgins 2010: 56). The performer is not looking to force repetition, like the "paranoid", technical, musician, but searching for the special moments, or a sensation that cannot be thought, only experienced. Being open to the possibilities inherent in the music and the performance brings forth a "thought without image" that frees a notion of difference in itself (Deleuze 2004: 208). Here, then, I have argued for authenticity to be understood as a refreshing, creative, and unique experience, as a deterritorialization of the intensities involved, blowing apart what we already know in order to arrive at new ways of making music. The participation at this level with possibilities in a process of becoming, achieves an experience of the authentic in music performance, which in turn enables a deep engagement by the musician with both the music and audience.

\section{Endnotes}

${ }^{1}$ The change in the record industry in the last ten years, largely due to digitization and the internet, has led to the increased importance of touring as a way for musicians to earn money. For the top earners live music is seen as the "biggest revenue stream" (O'Malley Greenburg 2013: online), this being supported by the 360 deal (Marshall 2013). While from my own experiences, and others in this study, income from touring finances new recordings, as well as being an important source of income (Cook 2012).

\section{Bibliography}

Anderson, L. (2006) Analytic Autoethnography. Journal of Contemporary Ethnography. 35 (4): 373-395. http://dx.doi.org/10.1177/0891241605280449

Atkinson, P. and Hammersley, M. (1994) Ethnography and Participant Observation. In Norman K. Denzin and Yvonna S. Lincoln Ed. Handbook of Qualititative Research. London: Sage: 248-261.

Auslander, P. -

(2006) Liveness: Performance and the Anxiety of Simulation. In Andy Bennett, Barry Shank, and Jason Toynbee Ed. The Popular Music Studies Reader. New York and London: Routledge: 85-97.

(1998) Seeing is Believing: Live Performance and the Discourse of Authenticity in Rock Culture. Literature and Psychology, 44 (4): 1-26.

http://lcc.gatech.edu/ auslander/publications/seeing.pdf Accessed 13 February 2012.

Becker, H., S. and Faulkner, R. R. (2008) Studying Something You Are Part Of: The View From the Bandstand. Ethnologie Française 38: 15-21. http://www.univparis1.fr/fileadmin/laboratoire.../BeckerFaulkner.pdf Accessed 23 April 2012.

Bell, J. (2005) Doing Your Research Project: A Guide for First-Time Researchers in Education, Health and Social Science. Maidenhead: Open University Press.

Bernard, H. R. (1988) Research Methods in Cultural Anthropology. London: Sage.

Bogue, R. (2004) Violence in Three Shades of Metal: Death, Doom and Black. In lan Buchanan and Marcel Swiboda Ed. Deleuze and Music. Edinburgh: Edinburgh 
University Press: 95-117.

The British Recorded Music Industry (2013) Pop Still On Top As British Music Buying Tastes Revealed. BPI. http://www.bpi.co.uk/media-centre/pop-still-on-top-as-britishmusic-buying-tastes-revealed.aspx Accessed 10 April 2013.

Chaffin, R., Chen, C. and Lemieux, A. F. (2007) "It is Different Each Time I Play": Variability in Highly Prepared Musical Performance. Music Perception: An Interdisciplinary Journal. 24 (5): 455-472

Cook, J. (2012) Case Study: Indie Rock Composer-Performer. Future of Music Coalition. http://money.futureofmusic.org/case-study-a/2/ Accessed 11 December 2013.

Davidson, J. W. and Correia, J. S. (2001) Meaningful Musical Performance: A Bodily Experience. Research Studies in Music Education 17: 70-83. http://dx.doi.org/10.1177/1321103X010170011301

Deleuze, G. (2004) Difference and Repetition. Translated from French by Paul Patton. London: Bloomsbury.

Deloitte (2011) Keeping the Life in Live: A\&R Diversifies. http://www.deloitte.com/view/en GX/global/industries/technology-mediatelecommunications/tmt-predictions-2011/media2011/d97f8f036907d210VgnVCM2000001b56f00aRCRD.htm Accessed $15 / 04 / 2012$.

Denzin, N. K. (2006) Analytic Autoethnography, or Déjà Vu all Over Again. Journal of Contemporary Ethnography. 35 (4): 419-428. http://dx.doi.org/10.1177/0891241606286985

Duffett, M. (2003) Imagined Memories Webcasting as a "Live" Technology and the Case of Little Big Gig. Information, Communication \& Society 6 (3): 307-325. http://dx.doi.org/10.1080/1369118032000155267

Fikentscher, K. (2000) "You Better Work!": Underground Dance Music in New York. Hanover, NH: Wesleyan University Press.

Financial Times (2010) Live Music Boom Drives Off Recording Blues. http://www.ft.com/cms/s/0/c8ff8d50-ac85- 11df-8582-00144feabdc0.html Accessed 15/04/2012.

Frith, S. -

(2000) The Discourse of World Music. In Georgina Born and David Hesmondhalgh Ed. Western Music and its Others: Difference, Representation, and Appropriation in Music. Berkeley: University of California Press: 305-322

(2007) Live Music Matters. Scottish Music Review. 1 (1): 1-17. http://www.scottishmusicreview.org/index.php/SMR/article/viewFile/9/8

(2010) Analysing Live Music in the UK: Findings One Year into a Three-Year Research Project. Journal of the International Association for the Study of Popular Music. 1 (1): 1-30. doi:10.5429/2079-3871(2010)v1i1.3en.

(2012) Editorial. Social Semiotics 22 (5): 517-522. http://dx.doi.org/10.1080/10350330.2012.731894

Frith, S., Brennan, M., Cloonan, M. and Webster, E. (2013) The History of Live Music in Britain, Vol.1: 1950-1967. Farnham: Ashgate Publishing.

Gilbert, J. (2004) Becoming-Music: The Rhizomatic Moment of Improvisation. In Ian Buchanan and Marcel Swiboda Ed. Deleuze and Music. Edinburgh: Edinburgh University Press: 118-139

Gracyk, T. (1996) Rhythm and Noise: An Aesthetics of Rock. London: I.B. Taurus. 
Gray, D. E. (2004) Doing Your Research in the Real World. London: Sage Publications. Harris, P. (2012) 'Listen Up, Youngsters': Springsteen Offers Life Advice in SXSW Keynote. The Guardian. Thursday 15 March 201220.44 GMT http://www.guardian.co.uk/culture/2012/mar/15/bruce-springsteen-keynote-speechsxsw Accessed 15 March 2012.

Henriques, J. (2011) Sonic Bodies: Reggae Sound Systems, Performance Techniques, and Ways of Knowing. New York: Continuum.

Higgins, S. (2010) A Deleuzian Noise/Excavating the Body of Abstract Sound. In Brian Hulse and Nick Nesbitt Ed. Sounding the Virtual: Gilles Deleuze and the Theory and Philosophy of Music. Farnham: Ashgate: 51-76

Hytönen-Ng, E. (2013) Experiencing 'Flow' in Jazz Performance. Farnham: Ashgate.

Keil, C. -

(1966) Motion and Feeling Through Music. The Journal of Aesthetics and Art Criticism. 24 (3): 337-349. http://www.jstor.org/stable/427969. Accessed 19 April 2012

(2004) Groovology and the Magic of Other People's Music. Music Grooves: 1-11 http://www.musicgrooves.org/articles/GroovologyAndMagic.pdf Accessed 19 April 2012.

Leonard, M. (2007) Gender in the Music Industry: Rock, Discourse, and Girl Power. Aldershot: Ashgate.

Marshall, L. (2013) The 360 Deal and the 'New' Music Industry. European Journal of Cultural Studies. 16 (1): 77-99. doi: 10.1177/1367549412457478

Middleton, R. (1983) 'Play it again Sam': Some Notes on the Productivity of Repetition in Popular Music." Popular Music. 3: 235-270. http://www.jstor.org/stable/853102. Accessed 13 March 2012.

Moore, A. (2002) Authenticity as Authentication. Popular Music. 21 (2): 209-223. http://www.jstor.org/stable/853683 Accessed 15 April 2012.

O'Malley Greenburg, Z. (2013) The World's Highest Paid Musicians 2013. Forbes. http://www.forbes.com/sites/zackomalleygreenburg/2013/11/19/the-worlds-highestpaid-musicians-2013/ Accessed 11 December 2013.

Pattie, D. (1999) 4 Real. Authenticity, Performance and Rock Music. Enculturation. 2 (2). http://enculturation.gmu.edu/2 2/pattie.html Accessed 04 March 2012.

Perchard, T. (2011) Thelonious Monk Meets the French Critics: Art and Entertainment, Improvisation, and its Simulacrum. Jazz Perspectives. 5(1): 61-94.

PRS for Music (2012) Adding up the UK music industry 2011. PRS for Music. http://www.prsformusic.com/aboutus/corporateresources/reportsandpublications/add inguptheindustry2011/Documents/Economic\%20Insight\%2011\%20Dec.pdf\#page=1 \&zoom=auto, 0,849 Accessed 10 April 2013.

Quirk, T. and Toynbee, J. (2005) Going Through the Motions: Why Pete Townshend's Windmill Works Even When He Doesn't Mean It. Popular Music. 24 (3): 399-413. http://www.jstor.org/stable/3877526 Accessed 05/01/2012.

Szekely, M. (2003) Becoming-still: Perspectives on Musical Ontology After Deleuze and Guattari. Social Semiotics. 13 (2): 113-128. http://dx.doi.org/10.1080/1035033032000152561

Thornton, S. (1995) Club Cultures: Music, Media and Subcultural Capital. Cambridge: Polity Press.

Toynbee, J. (2000) Making Popular Music: Musicians, Creativity and Institutions. London: Arnold. 
Wald, E. (2009) How The Beatles Destroyed Rock ' $n$ ' Roll: An Alternative History of American Popular Music. Oxford: Oxford University Press.

Williams, J. (2003) Gilles Deleuze's 'Difference and Repetition. Edinburgh: Edinburgh University Press

Wills, G. and Cooper, C. L. (1988) Pressure Sensitive: Popular Musicians Under Stress. London: Sage Books.

Wolfreys, J. (2009) Off the Beaten Path or, Notes Towards a Heideggerian Deterritorialisation: A Response to Daniel Watt. In Laura Cull Ed. Deleuze and Performance. Edinburgh: Edinburgh University Press: 102-108.

Wu, E. M. (2010) Memory and Nostalgia in Youth Music Cultures: Finding the Vibe in the San Francisco Bay Area Rave Scene, 2002-2004. Dancecult: Journal of Electronic Dance Music Culture 1(2): 63-78.

http://dj.dancecult.net/index.php/journal/article/viewArticle/41 Accessed 10 April 2013. 